\title{
Fluctuations in Hawaii's humpback whale Megaptera novaeangliae population inferred from male song chorusing off Maui
}

\author{
Anke Kügler ${ }^{1,3, *}$, Marc O. Lammers ${ }^{2,3}$, Eden J. Zang ${ }^{2,3}$, Maxwell B. Kaplan ${ }^{4,5}$, \\ T. Aran Mooney ${ }^{4}$

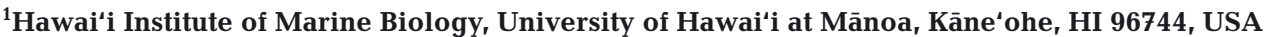 \\ ${ }^{2}$ Hawaiian Islands Humpback Whale National Marine Sanctuary, Kīhei, HI 96753, USA \\ ${ }^{3}$ Oceanwide Science Institute, Makawao, HI 96768, USA \\ ${ }^{4}$ Woods Hole Oceanographic Institution, Woods Hole, MA 02543, USA \\ ${ }^{5}$ Present address: Fisheries and Oceans Canada, Ottawa, ON K1A 0E6, Canada
}

\begin{abstract}
Approximately half of the North Pacific humpback whale Megaptera novaeangliae stock visits the shallow waters of the main Hawaiian Islands seasonally. Within this breeding area, mature males produce an elaborate acoustic display known as song, which becomes the dominant source of ambient underwater sound between December and April. Following reports of unusually low whale numbers that began in 2015/16, we examined song chorusing recorded through long-term passive acoustic monitoring at 6 sites off Maui as a proxy for relative whale abundance between 2014 and 2019. Daily root-mean-square sound pressure levels (RMS SPLs) were calculated to compare variations in low-frequency acoustic energy $(0-1.5 \mathrm{kHz})$. After 2014/15, the over-

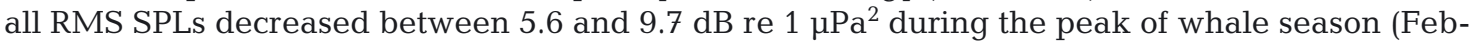
ruary and March), reducing ambient acoustic energy from chorusing by over $50 \%$. This change in song levels co-occurred with a broad-scale oceanic heat wave in the northeast Pacific termed the 'Blob,' a major El Niño event in the North Pacific, and a warming period in the Pacific Decadal Oscillation cycle. Although it remains unclear whether our observations reflect a decrease in population size, a change in migration patterns, a shift in distribution to other areas, a change in the behavior of males, or some combination of these, our results indicate that continued monitoring and further studies of humpback whales throughout the North Pacific are warranted to better understand the fluctuations occurring in this recently recovered population and other populations that continue to be endangered or threatened.
\end{abstract}

KEY WORDS: Humpback whale · Passive acoustic monitoring • Song chorusing • Population monitoring $\cdot$ Hawai'i $\cdot$ North Pacific $\cdot$ El Niño $\cdot$ The Blob

\section{INTRODUCTION}

Humpback whales Megaptera novaeangliae are baleen whales (mysticetes) of the family Balaenopteridae that migrate annually between high-latitude summer feeding habitats and low-latitude winter breeding grounds. These whales occur globally and have discrete populations in the different ocean

\footnotetext{
*Corresponding author: akuegler@hawaii.edu
}

basins. The US National Oceanic and Atmospheric Administration (NOAA) National Marine Fisheries Service (NMFS) currently divides the global population into 14 distinct population segments (DPSs) (NOAA NMFS 2016). Like most large whales, humpbacks were depleted through commercial whaling in the $20^{\text {th }}$ century (Rocha et al. 2015), and while most populations have since recovered and are increasing,

(C) The authors 2020. Open Access under Creative Commons by Attribution Licence. Use, distribution and reproduction are unrestricted. Authors and original publication must be credited. 
some populations remain small and are still classified as Endangered or Threatened (Childerhouse et al. 2008, NOAA NMFS 2016). In the North Pacific, humpback whales spend the summers in subarctic and arctic regions such as British Colombia, Alaska, Kamchatka, and the Bering Sea and migrate to their tropical breeding grounds in Hawai'i, Mexico, Central America, southern Japan, and the Philippines (Baker et al. 1986, Calambokidis et al. 2008, Clapham 2008, NOAA NMFS 2016).

The Main Hawaiian Islands (MHI) — the largest islands of the Hawaiian archipelago consisting of Hawai'i Island (or Big Island), O'ahu, Kaua'i, Ni'ihau, and the 4-island region of Maui, Moloka'i, Lāna'i, and Kaho'olawe called Maui Nui-are among the most important breeding grounds for North Pacific humpback whales, with more than half of the total North Pacific stock wintering in the islands (Herman \& Antinoja 1977, Calambokidis et al. 2008). The Northwestern Hawaiian Islands (NWHI), extending for $1900 \mathrm{~km}$ northwest of the MHI over a total area of $8048 \mathrm{~km}^{2}$ ranging northward to $28^{\circ} \mathrm{N}$, have also been proposed as a wintering area (Johnston et al. 2007, Calambokidis et al. 2008, Lammers et al. 2011), but to date comparatively little effort has been made to document humpback whale use of this part of the archipelago.

In 2016, 9 humpback whale DPSs, including the one that winters in Hawai'i, were delisted from the US Endangered Species Act. This followed decades of recovery at an estimated annual growth rate of ca. 6-7\% (Mobley et al. 1999, 2001, Calambokidis et al. 2008, NOAA NMFS 2016). However, starting in the 2015/16 breeding season, reports from ocean users, researchers, and citizen science whale counts indicated that fewer whales were observed in Hawaiian waters and also in other parts of the North Pacific (Neilson et al. 2017, 2018, Cartwright et al. 2019, NOAA 2019). The observed trends have resulted in renewed concerns about the status of the Hawaiian DPS (NOAA 2019).

On the breeding grounds, males produce a complex acoustic display known as 'song' (Payne \& McVay 1971, Winn \& Winn 1978). Song is hypothesized to play an important function for mating and is potentially directed at other males (Darling et al. 2006; see Herman 2017 for a comprehensive review on the function of song). Male song chorusing becomes the dominant contributor to ambient acoustic energy during the winter months in many parts of the breeding grounds, with many whales singing concurrently in an asynchronous manner (Au et al. 2000, Seger et al. 2016). Increases and decreases in chorus- ing amplitude correlate with the arrival, peak presence, and departure of whales from the breeding grounds, indicating that chorusing levels can be a useful indicator of relative whale presence (Au et al. 2000, Seger et al. 2016, Noad et al. 2017).

Acoustic monitoring of the breeding grounds is a cost-efficient method of investigating patterns of humpback whale presence over extended timeframes (Zimmer 2011, Seger et al. 2016). Long-endurance, bottom-moored recorders can capture the singing activity of whales and thereby provide a quantitative metric of the presence of the males in monitored areas. The objective of this study was to use acoustic monitoring to examine whale presence off Maui during the breeding season from 2014/15 to 2018/19. Male humpback whale song chorusing was used as a proxy to quantitatively evaluate the reported changes in whale abundance in Hawai'i beginning in 2015 .

\section{MATERIALS AND METHODS}

\subsection{Data collection}

Acoustic data were collected during multiple continuous and non-continuous timeframes between September 2014 and May 2019, with a particular focus on the humpback whale season between November and April of each year, at 6 locations off Maui, Hawai'i (Fig. 1), using 3 deep-water and 3 shallow-water bottom-moored, autonomous ecological acoustic recorders (EARs; Lammers et al. 2008). Deployment location, depth, and recording periods for each year are summarized in Table 1. All sites were located on coral reef (Kahekili, Olowalu), sand (MM17), or rock bottom (Maui6, Maui7, Maui8) within or near the $200 \mathrm{~m}$ isobath, which is considered to define the preferred humpback whale habitat in Hawai'i (Herman \& Antinoja 1977, Mobley et al. 1999). Shallow EARs were anchored to concrete blocks on the bottom and were deployed by divers; deep EARs were coupled with a syntactic foam float, 2 Sub Sea Sonics AR-60 acoustic releases, and approximately $75 \mathrm{~kg}$ of sandbags to anchor the mooring. Deep EARs were deployed off a small vessel and sited in the water column approximately $4 \mathrm{~m}$ off the bottom. Some deployments were originally part of other projects, dictating recovery schedules and instrument settings. Logistics and weather limited the accessibility of some sites, causing occasional delays between recovery and re-deployment of EARs, which resulted in gaps in the data series (cf. Table 1). 


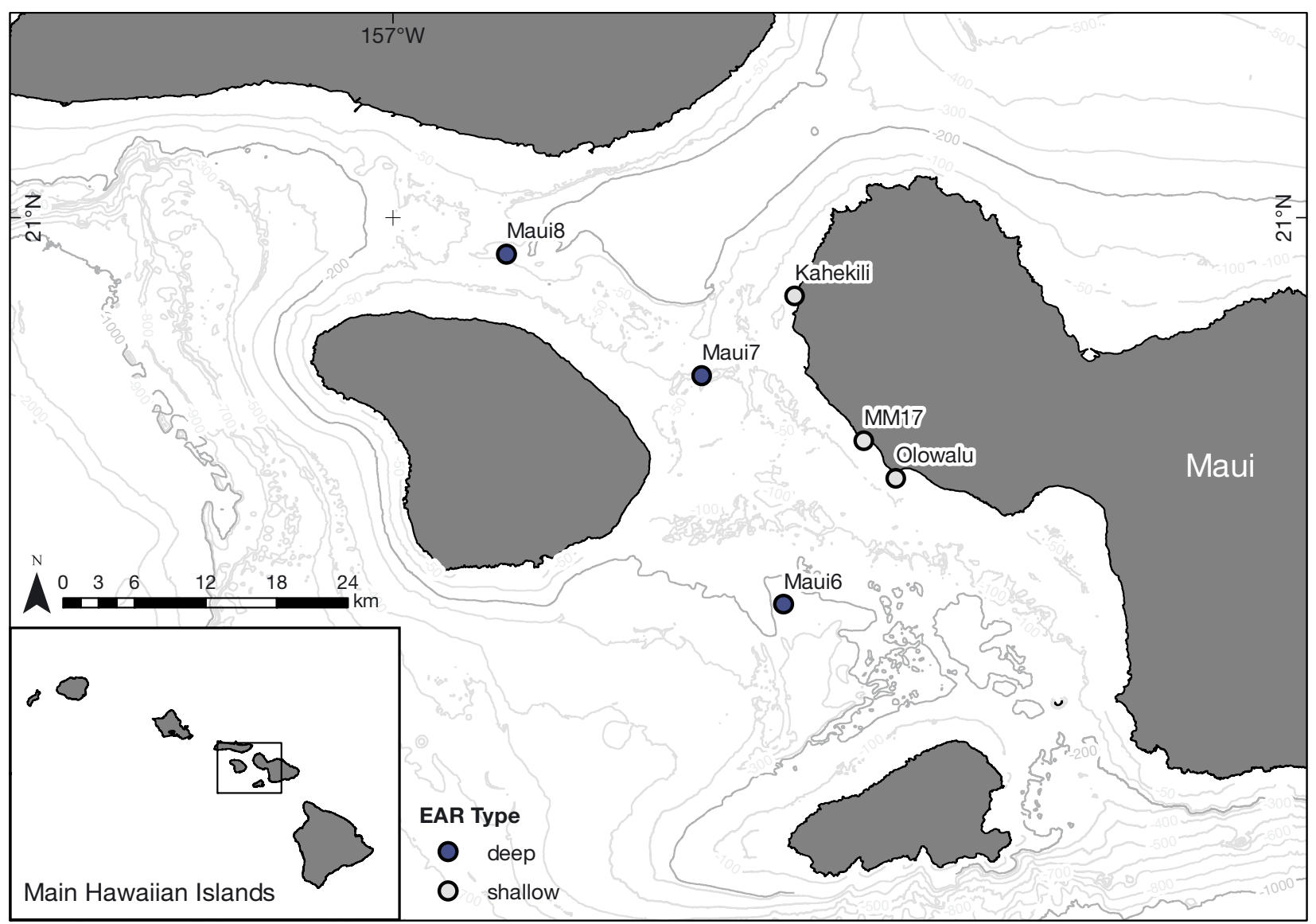

Fig. 1. Study area and shallow (light grey) and deep (dark grey) ecological acoustic recorder (EAR) locations. Inset shows the position of the study area within the Main Hawaiian Islands. Dark lines represent the 200 and $1000 \mathrm{~m}$ isobaths

One EAR (MM17) malfunctioned in January 2016, and all subsequent data from this site were excluded from further analysis except data from the 2018/19 season. The EARs recorded using a 25, 50, or $64 \mathrm{kHz}$ sample rate at a $10 \%$ duty cycle, or $30 \mathrm{~s}$ 'on' every $5 \mathrm{~min}$.

Table 1. Summary of ecological acoustic recorder (EAR) locations, depths, and continuous recording periods between 2014 and 2019 for 3 shallow and 3 deep EARs off Maui, Hawai'i, USA. Dates are given as mm/dd. Dates shown in light grey indicate days that were excluded from analysis due to instrument malfunction or incomplete data; -: years in which no data were collected

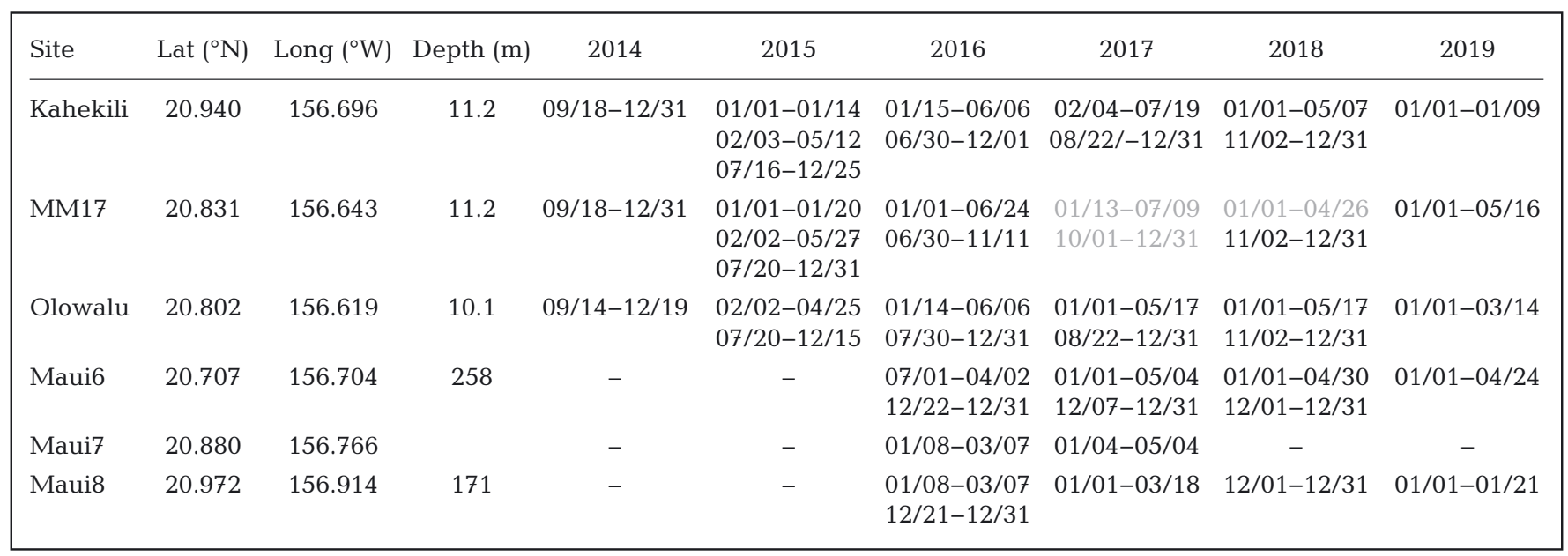




\subsection{Data processing and analysis}

The acoustic energy from the cumulative amount of singing (spectrogram of chorus: Fig. 2) is used as a relative metric of whale abundance under the assumptions that the amount of chorusing is proportional to the number of whales, the proportion of singing whales is population size-independent, and the spatial density of singers is fixed. All recordings were down-sampled to a $3 \mathrm{kHz}$ sample rate using MATLAB (MATLAB and Statistics Toolbox Release 2015b, The MathWorks), resulting in a $0-1.5 \mathrm{kHz}$ analysis bandwidth, which corresponds to the range where the majority of humpback whale song units have their peak frequencies (Payne \& McVay 1971, $\mathrm{Au}$ et al. 2006). EARs have a hardwired high-pass filter at $20 \mathrm{~Hz}$. No further filtering was applied. A custom MATLAB program was used to convert the $30 \mathrm{~s}$ recording into $\mathrm{dB}$ values and then calculate the rootmean-square sound pressure level (RMS SPL), a measure of the acoustic energy for each file in $\mathrm{dB}$ re $1 \mathrm{\mu Pa}^{2}$, as

$$
\text { RMS SPL }=20 \log \sqrt{\frac{1}{T} \int_{0}^{T} p^{2}(t) d t}
$$

where $T$ is the duration of each file (30 s) and $p(t)$ is the pressure $p$ re $1 \mu \mathrm{Pa}^{2}$ at time $t$. Decibel unit reporting follows standards described by Ainslie et al. (2018).

All statistical analyses were conducted in R 3.3.2 ( R Core Team 2016). The median RMS SPL in dB re $1 \mathrm{\mu Pa}^{2}$ was calculated for each day of monitoring and location to reduce auto-correlation within the time series, as recordings are not independent from each other when song continues over several files. A test for auto-correlation using the 'pacfc()' function from the 'stats' package in $\mathrm{R}$ showed a strong correlation up to lag 10 (50 min) and some correlation up to lag $25(2 \mathrm{~h})$, but no auto-correlation at lag $288(24 \mathrm{~h})$. Averaging by day also avoids pseudo-replication from individual whales singing close to the recorders, temporarily increasing the SPLs of individual recordings. The data were sub-sampled to only consider files from 1 November through 30 April of each year, if available. If data were not available for the entire time period, all available recordings were used. Days that were incomplete due to refurbishment or intermittent recording gaps caused by low batteries at the end of a deployment period were excluded A generalized additive model (GAM) using the 'mgcv' package (Wood 2006) tested the relationship between daily median RMS SPL, date, location, and season. The relationship is defined in the following equation

$$
\text { RMS SPL }=\alpha+\mathrm{f}_{1}(\mathrm{DOY})+\text { Site }+ \text { Season }+\varepsilon
$$

where DOY is day of the year, $\alpha$ is the intercept and $\varepsilon$ is the error. The maximal differences of mean RMS SPLs in $\mathrm{dB}$ re $1 \mathrm{\mu Pa}^{2}\left(\Delta \mathrm{dB}_{\max }=\text { mean[RMS SPL }\right]_{\min }-$ mean[RMS SPL $]_{\max }$ ) among years were calculated for each month between November and April. To test for seasonal peak shifts over the different years, the median per month was calculated for each site and season, and a generalized linear model (GLM) was fit using the equation

$$
\begin{aligned}
\text { RMS SPL }= & \alpha+\text { Month }+ \text { Site }+ \\
& \text { Month } \times \text { Season }+\varepsilon
\end{aligned}
$$

Data were smoothed with a running average of $\mathrm{n}=$ 10 with the 'TTR' package for visualization only.

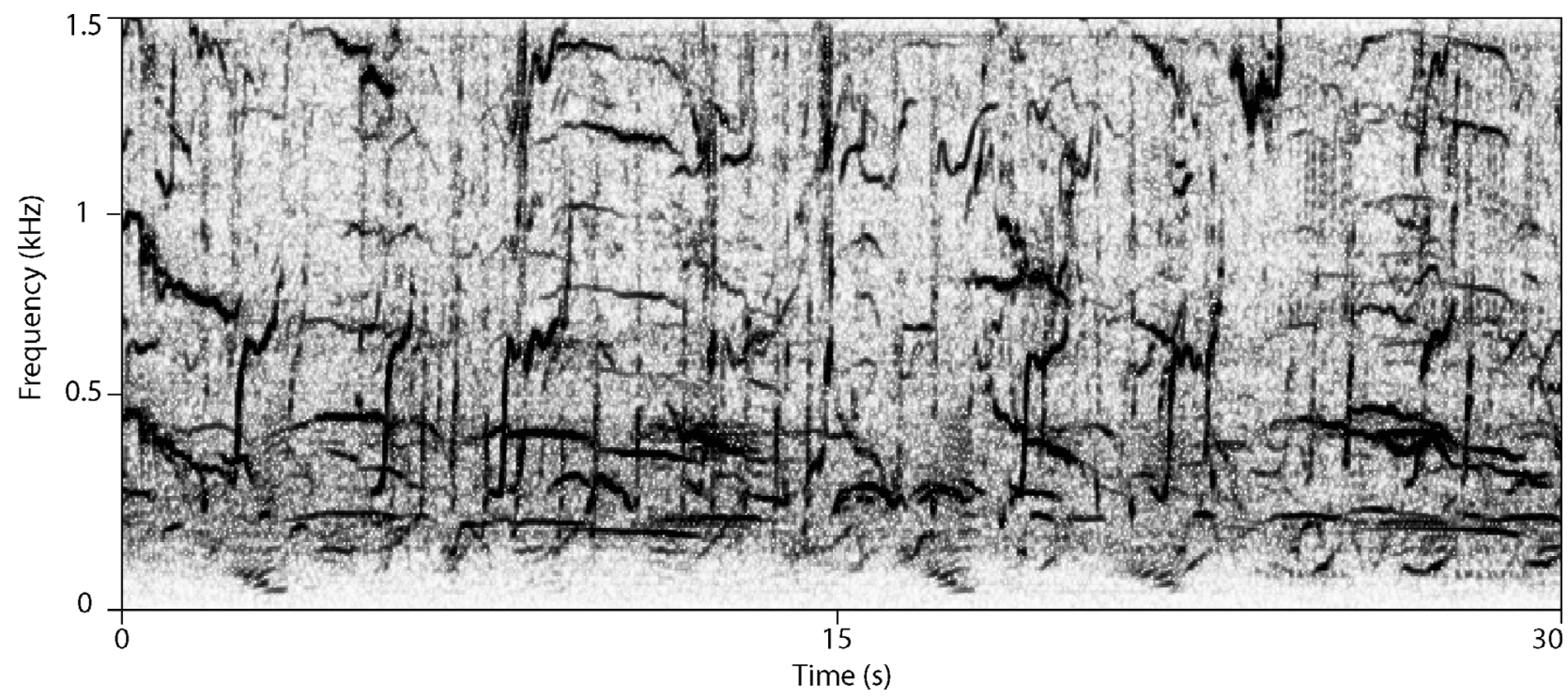

Fig. 2. Example spectrogram of humpback whale song chorusing off Maui, Hawai'i, between 0 and $1.5 \mathrm{kHz}$ 
Periods during the whale 'season' (defined as the timeframe between 1 February and 1 April) and 'offseason' (1 September to 31 October; 18 September to 31 October for 2014) were examined for possible baseline shifts over time, either due to changes in recorder sensitivity or in the ambient noise floor. For each year for which data were available, $15 \mathrm{~d}(\sim 25 \%)$ were randomly chosen for each period for which data were available. Only data from the 4 shallow-water sites were analyzed, as the deep-water EARs were deployed only during the whale seasons. A nonparametric Kruskal-Wallis test was performed to test for inter-annual differences within the whale season and during the off-season. If significant, a post hoc Dunn test with a Benjamini-Yekuteili-false-discoveryrate-corrected $\alpha$-value was performed with the 'dunn. test' package. The maximal differences $\Delta \mathrm{dB}_{\max }$ of mean RMS SPLs in $\mathrm{dB}$ re $1 \mathrm{\mu Pa}^{2}$ among years for both the season and the off-season time periods were calculated.

\section{RESULTS}

Recordings during the whale season were obtained for 2 to 5 consecutive years between 2014 and 2019 (Kahekili: 2014-2019, MM17: 2014-2016 and 20182019, Olowalu: 2014-2019, Molokini: 2013-2018, Maui6: 2015-2019, Maui7: 2016-2017, Maui8: 20152019; Fig. 3; Table 1). Additional data during summer and fall months were recorded for Kahekili between 2014 and 2017, MM17 between 2014 and 2016, and Olowalu between 2014 and 2017 (Table 1, see also Fig. S1 in the Supplement at www.int-res.com/ articles/suppl/n043p421_supp.pdf). RMS SPLs began to increase in November, peaked between February and March, before decreasing through April at all sites and during all monitored years (Figs. $3 \& 4$; Fig. S1). The GAM showed that during the season, daily median RMS SPLs were significantly predicted by day of the year $(F=2482, \mathrm{p}<0.001)$, site $(F=143.4$, $\mathrm{p}<0.001)$, and season $(F=336.1, \mathrm{p}<0.001)$, and explained $92.2 \%$ of deviance (Fig. 5). The significance of day of the year reflects the seasonality pattern and the significance of site reflects the impact of recorder location and depth on sound propagation. The GLM fitted on median monthly data showed that RMS SPL was significantly predicted by month ( $\mathrm{p}<$ $0.001)$, site $(p<0.001)$, season $(p<0.001)$, and the interaction between month and season ( $p<0.001)$. The significant interaction between month and season indicates a shift within the seasonal pattern among the different years.
Mean \pm SD RMS SPLs are summarized for each year, month, and site in Table S1. Between 2014/15 and 2017/18, decreasing trends of mean RMS SPL were observed at all recording sites (Figs. $3 \& 4$ ). During that timeframe, monthly mean levels decreased by as much as $9.7 \mathrm{~dB}$ (Table 2). In the 2018/ 19 season, levels went up to approximately 2015/16 levels during the peak of the season at all 3 sites for which data were available. At all sites, the onset of the whale season in November through January appeared to be similar, while the greatest deviations were observed during the peak and the end of the whale season from February through April (Fig. 3, Table S1). For most sites, the peak of the season shifted and narrowed over time from late-February/ mid-March to late-January/mid-February until 2017/ 18, and back to March in 2018/19 (Fig. 3). The greatest maximal dB level differences in March and April indicate whales generally appearing to depart earlier (Fig. 3, Table 2). Only at the deep-water Maui8 site did the peak shift later during the 2 years for which data are available.

\subsection{Kahekili}

SPLs at Kahekili showed a continuous decreasing trend between 2014/15 and 2017/18. The maximal difference in $\mathrm{dB}$ levels ranged from $-1.7 \mathrm{~dB}$ in November to $-8.0 \mathrm{~dB}$ in March and was greater than $-5.5 \mathrm{~dB}$ in February and April (Table 2). The peak of the season shifted from late March in 2014/15 to midFebruary. No data were available after 9 January 2019, but the gradually increasing levels in December matched previous years (Figs. $3 \& 4$, Table S1).

\subsection{MM17}

Only 3 years of data are available for MM17. Between 2014/15 and 2015/16, chorusing levels decreased by a maximum of 3.9-6.7 dB between January and April, although the maximal difference during the peak month of February was approximately $-2 \mathrm{~dB}\left(\Delta \mathrm{dB}_{\max }=-1.9 \mathrm{~dB}\right.$, Table 2$)$. This decrease over 2 seasons in February is comparable to the 2 deepwater sites at Maui7 and Maui8 (see Section 3.5). A secondary mid-March peak in 2014/15 was absent in 2015/16. In 2018/19, chorusing levels in February and March returned to those measured in 2014/15 (Figs. 3 \& 4, Table S1), but remained lower in January and April, indicating a later arrival and earlier departure. 

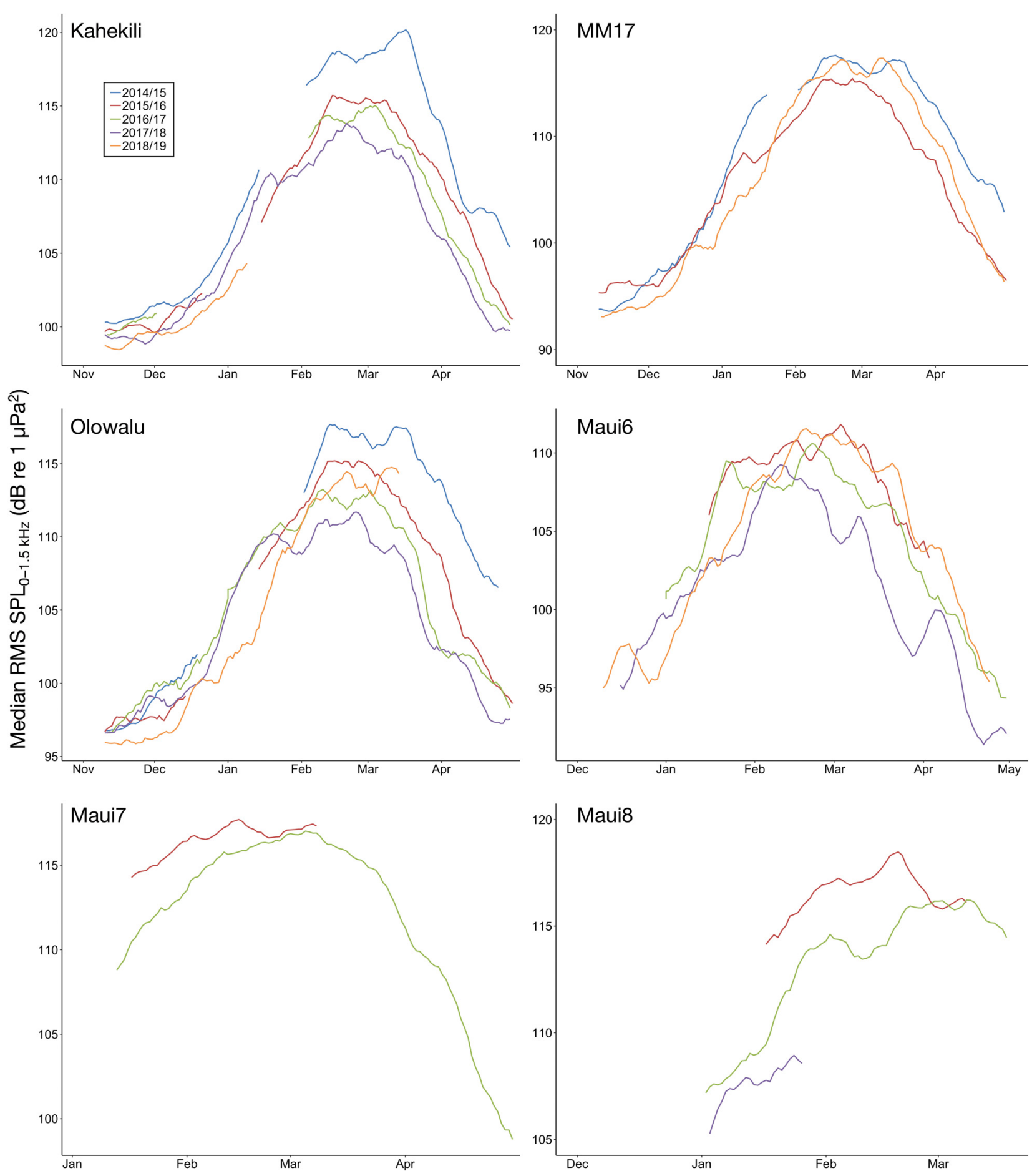

Fig. 3. Median daily root-mean-squared sound pressure levels (RMS SPLs) in dB re $1 \mu \mathrm{Pa}^{2}$ in the $0-1.5 \mathrm{kHz}$ frequency band, smoothed with a running average of $\mathrm{n}=10$, between 1 November and 30 April for 3 shallow (Kahekili, MM17, Olowalu) and 3 deep (Maui6, Maui7, Maui8) ecological acoustic recorder (EAR) sites off Maui, Hawai'i

\subsection{Olowalu}

Mean RMS SPLs decreased from 2014/15 to 2017/18 and ranged between $-2.1 \mathrm{~dB}$ in November and -9.7 dB in March (Fig. 3, Table 2). Of all sites, Olowalu saw the greatest drop during the peak months of February and March as well as towards the end of the season in April (Table 2). The peak gradually shifted earlier over the 4 seasons (Fig. 4). In 2018/19, levels in January remained lower than in previous years, but 

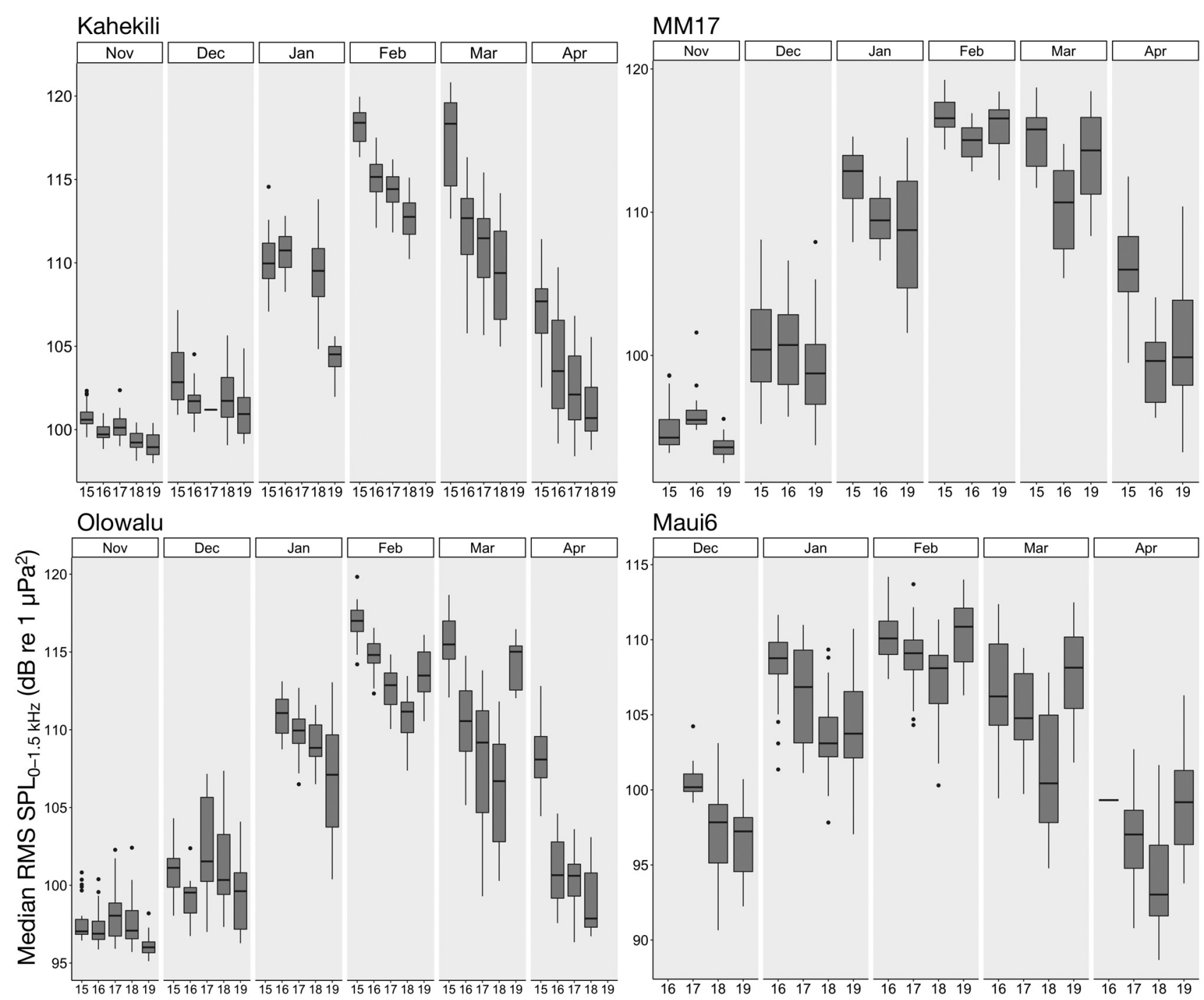

Maui6

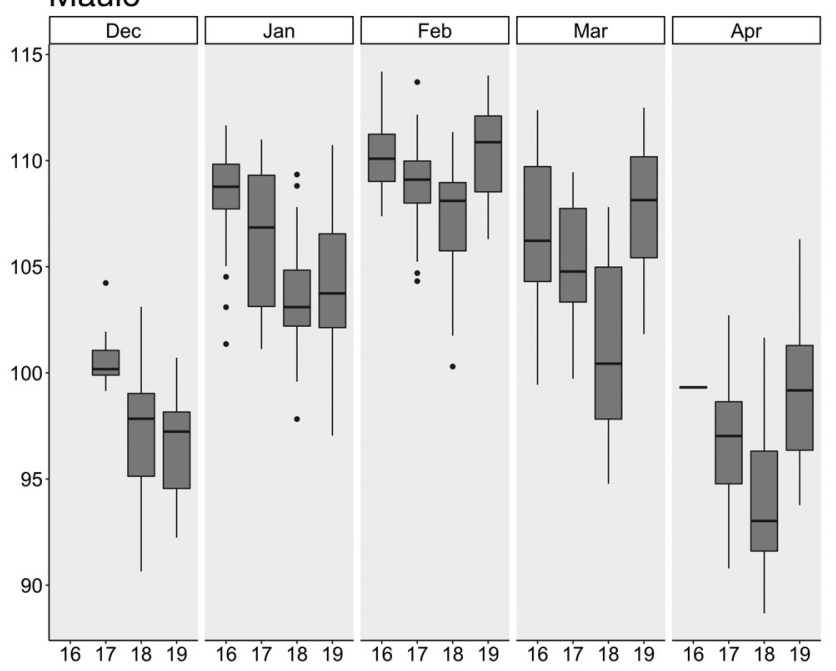

Maui7

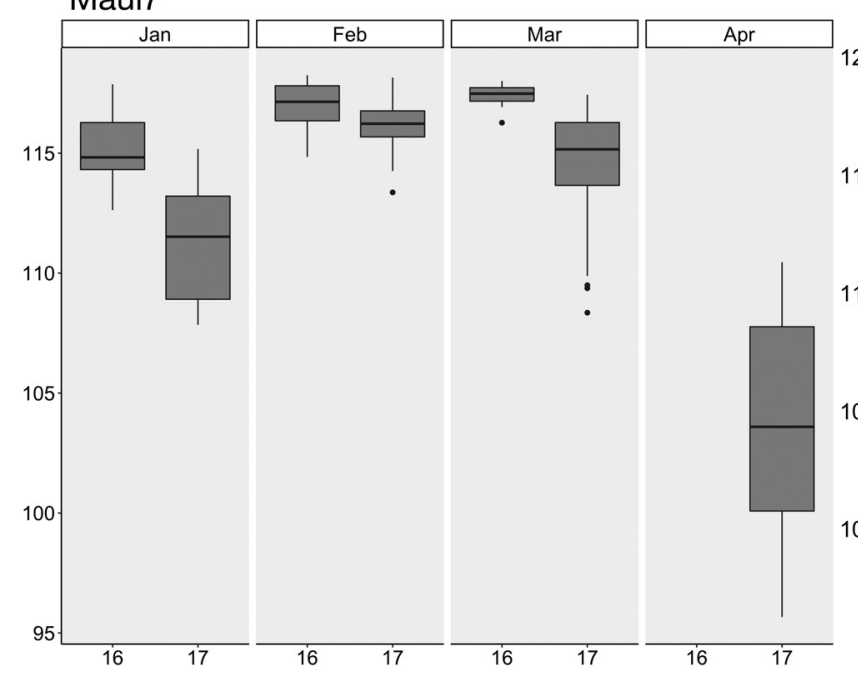

Maui8

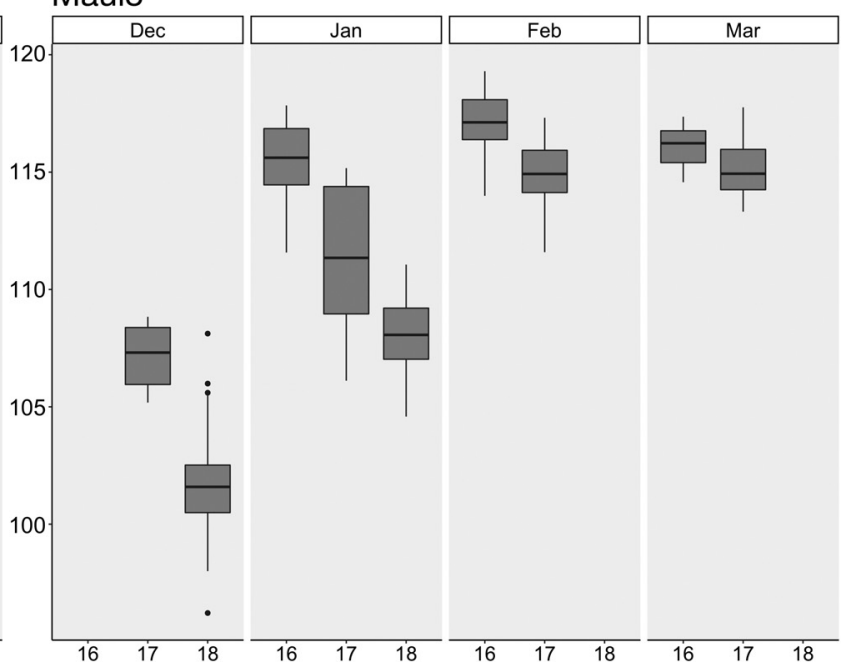

Fig. 4. Comparison per whale season of daily median root-mean-square sound pressure levels (RMS SPLs) in dB re $1 \mu P a^{2}$ for 6 sites off Maui, Hawai'i, grouped by month. Center line: median, hinges: first and third quartiles, whiskers: $1.5 \times$ inter-quartile range, points: outliers. $x$-axis labels correspond to the second year of each winter season, i.e. $15=2014 / 15$ whale season 

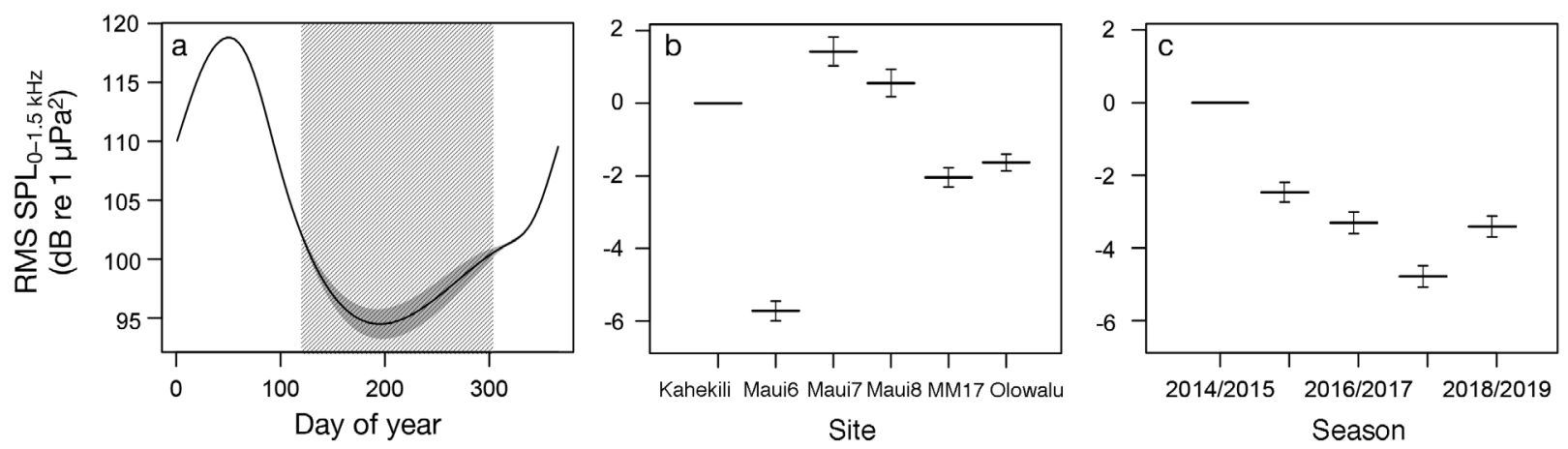

Fig. 5. Generalized additive model results with standard errors for daily median root-mean-square sound pressure levels (RMS SPLs) in dB re $1 \mu \mathrm{Pa}^{2}$ at 6 sites off Maui, Hawai'i, with (a) 1 continuous (day of year) and (b,c) 2 categorical explanatory variables (b: site, c: season). Shaded area in (a) indicates off-season timeframe between 1 May and 31 October for which no data were included for the model

Table 2. Maximal difference between lowest and highest monthly mean root-mean-square sound pressure levels (RMS SPLs) in $\mathrm{dB}$ re $1 \mathrm{\mu Pa}^{2}\left(\Delta \mathrm{dB}_{\max }\right)$ during the 2015-2019 whale season for each ecological acoustic recorder (EAR) site off Maui, Hawai'i. Years shown in grey indicate the respective seasons of the lowest and the highest monthly means for each site and month

\begin{tabular}{|ccccccc|}
\hline & Nov & Dec & Jan & Feb & Mar & Apr \\
\hline Kahekili & $2018 / 19-2014 / 15$ & $2018 / 19-2014 / 15$ & $2017 / 18-2015 / 16$ & $2017 / 18-2014 / 15$ & $2017 / 18-2014 / 15$ & $2017 / 18-2014 / 15$ \\
MM17 & -1.7 & -2.3 & -1.3 & -5.6 & -8.0 & -5.9 \\
& $2018 / 19-2015 / 16$ & $2018 / 19-2014 / 15$ & $2018 / 19-2014 / 15$ & $2015 / 16-2014 / 15$ & $2015 / 16-2014 / 15$ & $2015 / 16-2014 / 15$ \\
Olowalu & $2018 / 19-2016 / 17$ & $2015 / 16-2016 / 17$ & $2018 / 19-2015 / 16$ & $2017 / 18-2014 / 15$ & $2017 / 18-2014 / 15$ & $2017 / 18-2014 / 15$ \\
Maui6 & -2.1 & -3.3 & -4.0 & -6.1 & -9.7 & -9.2 \\
Maui7 & & $2018 / 19-2016 / 17$ & $2017 / 18-2015 / 16$ & $2017 / 18-2015 / 16$ & $2017 / 18-2018 / 19$ & $2017 / 18-2015 / 16$ \\
& & -4.4 & -4.7 & -3.3 & -6.4 & -5.1 \\
Maui8 & & & $2016 / 17-2015 / 16$ & $2016 / 17-2015 / 16$ & $2016 / 17-2015 / 16$ & -2.9 \\
& & $2018 / 19-2016 / 17$ & $2018 / 19-2015 / 16$ & $2016 / 17-2015 / 16$ & $2016 / 17-2015 / 16$ \\
\hline
\end{tabular}

reached approximately 2015/16 levels in February and early March (Figs. 3 \& 4, Table S1). The EAR stopped recording in mid-March, and it appears that by this time, the peak of the season had not yet passed (Fig. 3).

\subsection{Maui6}

No data were available for 2014/15, but RMS SPLs at the deep-water Maui6 site showed a decreasing trend between 2015/16 and 2017/18, with maximal differences ranging from $-4.4 \mathrm{~dB}$ in December to $-6.4 \mathrm{~dB}$ in March and April (Fig. 3, Table 2). Maui6 data showed an obvious narrowing of the peak of the season, with levels already starting to drop in early February in 2017/18 (Fig. 3). In the 2018/19 season, chorusing levels matched those of 2015/16 during the peak and the end of the season, but remained lower in January (Figs. 3 \& 4, Table S1).

\subsection{Maui7 and Maui8}

Data for the deep-water Maui7 and Maui8 sites were limited. Noise levels at Mauif were lower by 3.9 dB in January 2016/17, but reached 2015/16 lev-

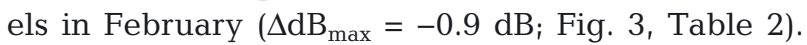
The EAR stopped recording in early March 2015/16, and no conclusion can be reached on when the peak occurred during that season at this location. SPLs at Maui8 dropped by $-7.5 \mathrm{~dB}$ in January between 2015/16 and 2016/17 and differed by -2.2 dB in February (Table 2). Chorusing levels increased more slowly in 2016/17, with a later peak in March instead of mid-February, with similar March levels as in 2015/16 ( $\Delta \mathrm{dB}_{\max }=-0.66 \mathrm{~dB}$; Fig. 3, Table 2$)$. Data for 
the 2018/19 season were inconclusive because the recorder stopped recording in mid-January.

\subsection{Season vs. off-season}

To examine possible differences in longitudinal noise level changes between the peak of the whale season ('season': February through March) and the off-season where no whale presence is expected ('off-season': September through October), KruskalWallis tests of random sub-samples of $25 \%$ of days ( $\mathrm{n}=15$ ) were performed. These showed that RMS SPLs varied significantly among years during the season at all 3 shallow-water sites (Fig. 6). Except for MM17, levels did not vary significantly among years during the off-season (Fig. 6). Post hoc tests among years for each site are summarized in Table S2 and showed that during the off-season, levels at MM17 in

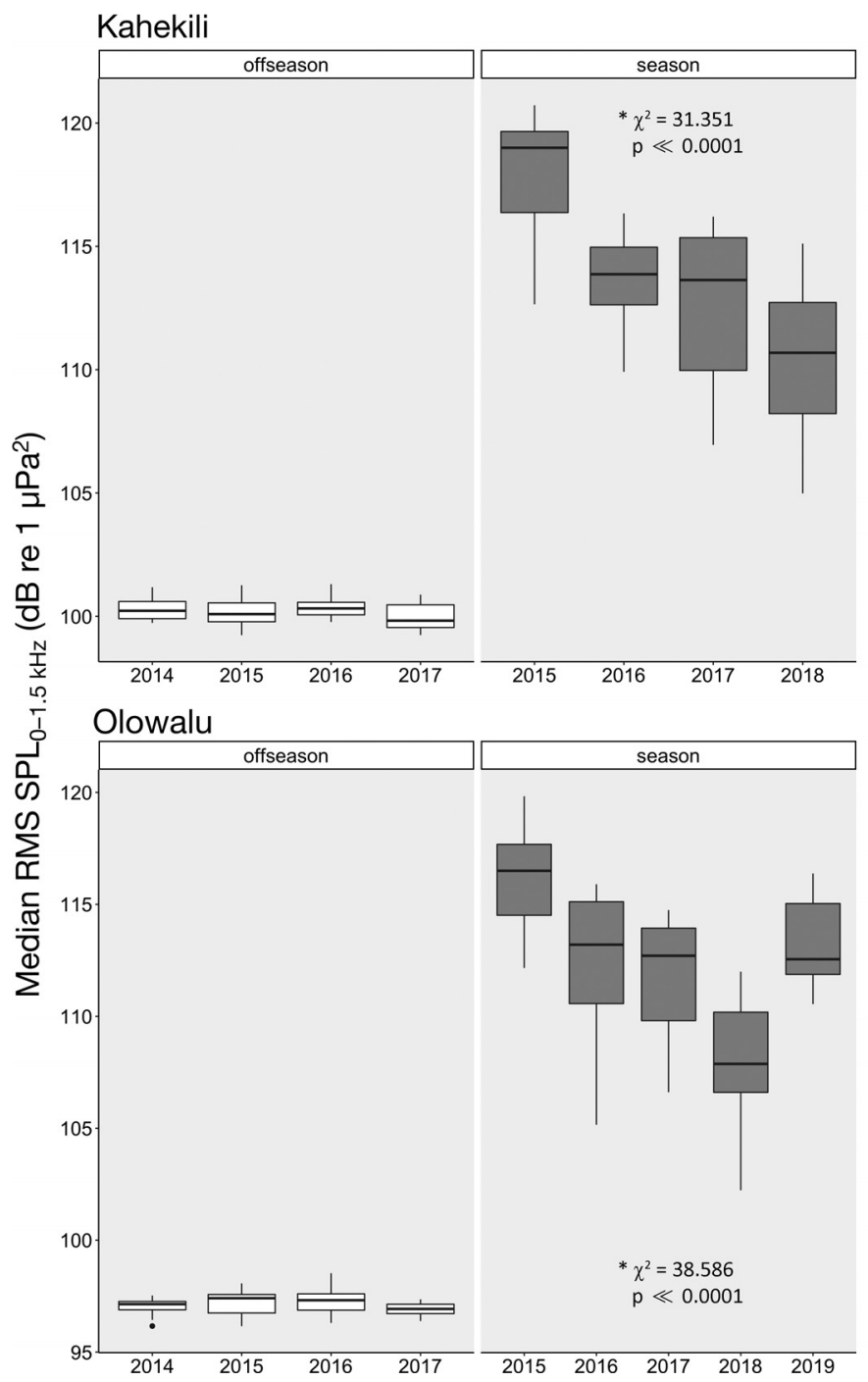

2014/15 were significantly lower than the subsequent 2 years (cf. Fig. 6). During the peak season, RMS SPLs were significantly higher in 2014/15 than in the 3 seasons from 2015/16 to 2017/18 at Kahekili and Olowalu and higher than 2015/16 and 2018/19 at MM17 (Fig. 6). Levels in 2018/19 at Olowalu were also significantly higher than the previous 2 seasons (Fig. 6).

The maximal difference over the entire study period was lower at all sites during the 2 off-season months $\left(\Delta \mathrm{dB}_{\text {max }}:-0.6\right.$ to $\left.-2.2 \mathrm{~dB}\right)$ than during the peak season months $\left(\Delta \mathrm{dB}_{\max }:-3.6\right.$ to $\left.-7.8 \mathrm{~dB}\right)$ and differed the least at MM17 (Fig. S2).

\section{DISCUSSION}

Humpback whales in Hawai'i have a staggered migration, with arrival and departure from the islands segregated by sex and age class (Craig et al. 2003).

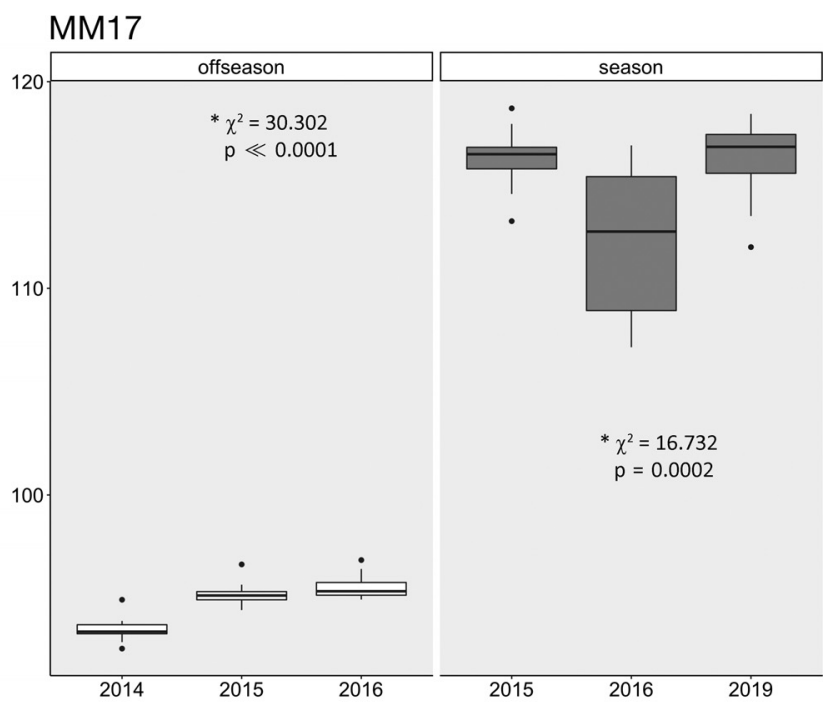

Fig. 6. Daily median root-mean-square sound pressure levels (RMS SPLs) in dB re $1 \mu^{2} \mathrm{~Pa}^{2}$ from $\sim 25 \%$ of days $(\mathrm{n}=15$ ) randomly selected for 3 shallow ecological acoustic recorder (EAR) sites off Maui, Hawai'i, between off-season (1 September and 31 October) and season (1 February and 30 March) for each year. Center line: median, hinges: first and third quartiles, whiskers: $1.5 \times$ inter-quartile range, points: outliers. ${ }^{*}$ Significant Kruskal-Wallis test $(\mathrm{p}<0.05)$ 
This creates a bell-shaped abundance curve that peaks between February and March that has been well established from visual and genetic studies in the past (Baker \& Herman 1981, Brown et al. 1995, Craig et al. 2003, Valsecchi et al. 2010). Au et al. (2000) showed that male song chorusing acoustically monitored at a shallow site off Maui followed the same pattern, an observation we confirmed at all of our study sites.

The 6 study sites monitored between 2014/15 and 2017/18 all showed a decreasing trend in the acoustic energy contributed by male song chorusing until 2018/19, when levels increased again at some sites. For every deployment at each respective site, the same hydrophone and processor were used for the entire study period to avoid bias caused by possible differences between recorders. From the comparison of off-season and season ambient levels, there was no evidence of shifts in instrument sensitivity through the duration of the multi-year deployments. Although a reduction of around $2 \mathrm{~dB}$ occurred in the off-season baseline noise floor at Kahekili and Olowalu in fall of 2015 (Fig. S1), this was likely due to changes in the behavior of snapping shrimp (Alpheus spp.), which are common on Hawaiian reefs. This interpretation is further supported by a lack of a similar drop in RMS SPLs at MM17, which is a sand-bottom area with minimal snapping shrimp activity. Thus, neither drifts in instrument sensitivity nor a decrease in baseline ambient noise levels appear to be the main cause of the lower levels recorded during the 2014/15 to 2018/19 whale seasons. It is important to point out that we work under the assumptions that the spatial density of singers in the area is fixed as well as that the proportion of singers is independent of the local population size. In fact, Noad et al. (2017) showed that off the east coast of Australia, the percentage of singers decreased with increasing overall number of observed whales. However, that study was conducted within the whales' migratory corridor, where whale behavior can differ in many ways from the breeding grounds. Therefore, the relationship between the numbers of singers and population density should be explicitly examined for the Hawaiian breeding grounds. Given that a $-6 \mathrm{~dB}$ change in RMS SPLs represents a 50\% decrease in acoustic energy, the decreases in chorusing levels observed, which were as great as $-9.5 \mathrm{~dB}$, likely cannot be explained without considering a substantial change in the occurrence and/or activity of singing whales.

While the exact function of male song remains debated, there is consensus that it plays some function within the mating system of humpback whales (Winn \& Winn 1978, Herman et al. 1980, Winn et al.
1981, Tyack 1983, Tyack \& Whitehead 1983, Baker \& Herman 1984, Darling \& Bérubé 2001, Darling et al. 2006, 2012, Herman 2017, Cholewiak et al. 2018). Abating singing could indicate a shift in male focus towards other means of intra-sexual competition, such as physical combat (Au et al. 2000), or it could be a direct reaction to lower numbers of receptive females. A recent study found evidence that humpback whales reduce their singing activity in the presence of shipping noise (Tsujii et al. 2018). Off Kaua'i, it was recently shown that while humpback whales do increase their source levels with increased background noise levels, they do so at a much lower rate than other marine mammals (Helble et al. 2020). Off Maui, the majority of anthropogenic noise within Hawaiian Islands Humpback Whale National Marine Sanctuary (HIHWNMS) waters originates from commercial whale-watching tour operators and commercial and recreational small-vessel fishing and other boating activities, and Au \& Green (2000) concluded that noise from whale watching and similar sources is unlikely to impact humpback whales in Hawai'i. A much louder high-speed jet-propelled craft traveling between O'ahu and Maui, which could potentially impact whale hearing and vocalizations, was decommissioned in 2009 (Rudd 2015).

Another possible explanation for the observed trends is small-scale changes in habitat use by the whales. Whales could have shifted further offshore within the area, perhaps in response to increasing commercial and recreational vessel activity (Lammers et al. 2013, Currie et al. 2014, 2017). Singers were also observed in deeper waters outside the $200 \mathrm{~m}$ isobath off Hawai'i Island in the past (Frankel 1994). However, none of our deep-water sites saw a concurrent increase in levels with decreases at near-shore sites. While whales may have moved to other areas within the MHI that were not acoustically monitored, changes in whale numbers were observed over a large area in the MHI, and small-scale redistributions are unlikely to be the cause of the decrease in song chorusing (NOAA 2019).

The NWHI, stretching $1900 \mathrm{~km}$ northwest of the MHI, have been proposed as humpback whale wintering habitat (Johnston et al. 2007, Calambokidis et al. 2008, Lammers et al. 2011). The abundance of whales in the NWHI and how whales use the region (i.e. whether they simply migrate through or use the area in the same way for mating and calving as the grounds in the MHI) is still unknown. It is also unknown whether whales in the NWHI are part of the MHI breeding assemblage or their own discrete population (Chen 2017). Furthermore, the NWHI are 
remote and protected as part of the Papahānaumokuākea Marine National Monument (PMNM), making them difficult to access and survey. If whales shifted from the MHI towards the islands, atolls, and banks in PMNM, it probably went unnoticed and due to lack of historic data would be difficult to determine. Future work within the NWHI could shed light not only on this question, but also on how the whales use the region in general and on their population status.

More likely than the previously discussed causes, the trends in chorusing levels described here are primarily the result of abundance changes, an explanation that is supported by visual surveys that reported similar findings (Cartwright et al. 2019, NOAA 2019) as well as data from the HIHWNMS Ocean Count project, a citizen science effort visually counting whales from multiple sites on O'ahu, Kaua'i, and Hawai'i Island on $1 \mathrm{~d}$ each month from January through March (unpublished data, raw data accessible at https:// hawaiihumpbackwhale.noaa.gov/involved/oceancount.html). Since the 1970s, the Hawai'i DPS increased from several hundreds of whales to more than 10000 , about half of the entire North Pacific stock (Mobley et al. 1999, 2001, Calambokidis et al. 2008). This recovery is relevant when considering the effect of natural population dynamics on population sizes. Populations grow until they reach their carrying capacity $(K)$, after which competition over limited resources limits further increases and the number of individuals fluctuates around $K$ (Fowler 1981, Begon et al. 2006). No historic data exist on the carrying capacity for Hawaiian humpback whales for pre-whaling times, but it is possible that this population reached its maximum sustainable size by 2014/15 and the observed decreases are part of natural ecological processes regulating population growth. This is partly supported by the observed increase of chorusing in the 2018/19 season, which suggests that the population may now be oscillating around $K$.

Significantly, Pacific-wide oceanographic changes coincided with the period in question and may have additionally or perhaps primarily contributed to the observed trends in whale abundance (Gentemann et al. 2017). A warm-water persistence in the northeast Pacific nicknamed the 'Blob' occurred between 2014 and 2016 (Bond et al. 2015, Tseng et al. 2017). A major El Niño event that began impacting the Pacific started in May 2014 and lasted through June 2016 (L'Heureux et al. 2017). Further, 2015 and 2016 saw a positive phase in the Pacific Decadal Oscillation, a long-term cycle of oceanic heating and cooling (Mantua et al. 1997, Di Lorenzo \& Mantua 2016, Newman et al. 2016). The combination of these events re- sulted in abnormally high sea surface temperatures and weather extremes diverting from their usual patterns in many areas of the North Pacific occupied by humpback whales (Bond et al. 2015, Levine \& McPhaden 2016). Large-scale oceanographic events such as El Niño and other heat waves, such as the 'Blob,' have been shown to negatively impact primary and secondary productivity and as a result behaviors and distributions of marine organisms (Barber \& Chavez 1983, Tershy et al. 1991, Mackas \& Galbraith 2002), including cetaceans (Tershy et al. 1991, Tynan 1999, Benson et al. 2002, Ballance et al. 2006, Simmonds \& Isaac 2007). The extreme ocean conditions between 2014 and 2016 resulted in large-scale ecosystem changes, including reductions in primary productivity (Whitney 2015). These decreases have been linked to a wide range of mass mortality events in the North Pacific and the Gulf of Alaska over a variety of taxa, including the die-off of over 60000 common murres Uria aalge, the trophically dominant fish-eating seabird of the area (Bond et al. 2015, Cavole et al. 2016, Di Lorenzo \& Mantua 2016, Piatt et al. 2020). Humpback whales feed on a variety of prey including krill, sand lance, herring, and other small shoaling fish that are impacted by higher water temperatures (Jurasz \& Jurasz 1979, Baker et al. 1985, Benson et al. 2002, Mackas \& Galbraith 2002).

Female humpback whales are known to skip migrations to replenish depleted body resources from gestation and lactation (Craig \& Herman 1997, Straley 1999). Less is known about the factors influencing the migration of males, but if food resources are low or changing, males would also be expected to shorten or skip migration if they were not able to build up enough body fat for the long journey. Other cetaceans, such as gray whales Eschrichtius robustus, have been observed delaying or skipping their southbound migrations and expanding their feeding ranges in response to climate-driven changes in the Arctic ecosystem (Moore 2008). Cartwright et al. (2019) found a strong correlation of fluctuating reproductive rates of humpback whales in Maui with the climate anomalies in the North Pacific, and reported a decline of observed mother-calf pairs of $76.5 \%$ between 2013 and 2018. Researchers working in Glacier Bay, Alaska, an important feeding ground for humpbacks wintering in Hawai'i, also reported substantial declines in whale abundance in recent years (Neilson et al. 2017, 2018).

Our data showed not only lower overall chorusing levels, but also the greatest differences between 2014/15 and 2017/18 in March and April. This suggests that those acoustically active whales that did migrate to the islands left earlier than in the past. 
This may be another indication that whales changed their overall migratory behavior, leaving the breeding grounds early, either due to a lack of mates or exhausted body resources, or a combination of both. If the oceanographic events occurring in 2014-2017 were indeed the cause of lower whale numbers in Hawai'i, we would have expected to start seeing a return to normal conditions, and the increased chorusing levels during the 2018/19 season suggest this may be taking place. However, we saw a continuing decreasing trend in the 2016/17 and 2017/18 seasons, 2 seasons after the end of El Niño and the 'Blob,' indicating that humpback whales needed longer to return to their normal migratory behavior after this large-scale oceanographic event.

Although removed from the US Endangered Species list, the Hawaiian DPS continues to be protected under the Marine Mammal Protection Act and regulations within the HIHWNMS. The Mexican and the western North Pacific populations remain either threatened or endangered (NOAA NMFS 2016). While the observed apparent chorusing increase in 2018/19 is cautiously optimistic and in line with visual observations for that season (R. Cartwright pers. comm., E. Lyman pers. comm.), our results illustrate the importance of continued long-term monitoring of the Hawaiian DPS and the other populations. In long-lived animals such as humpback whales with late maturity and an average inter-calf interval of 3 or more years (Craig \& Herman 1997), substantial changes at the population level are expected to be slow to become apparent. Large-scale climate events are an important factor that appear to lower the carrying capacity of North Pacific humpback whales and need to be considered when assessing the sustainability of a population. The cumulative impacts of anthropogenic interference through fisheries, oil and gas exploration, ship strike and entanglement threats, tourism, and other commercial and recreational activities, as well as climate change are predicted to increase and are particularly challenging for migrating animals that face different stressors in their respective habitats (Moore 2008, Lammers et al. 2013, Senigaglia et al. 2016). Off the US east coast, endangered North Atlantic right whales Eubalaena glacialis are currently declining after an initial increasing population trend following the ban on commercial whaling (Kraus et al. 2005). Our results warrant further studies of humpback whale populations throughout the North Pacific, including potential habitat shifts into previously unstudied and unknown regions, to understand the observed changes that appear to extend beyond the Hawaiian humpback whale breeding assemblage.
Acknowledgements. Funding was provided by The WHOI Access To The Sea initiative and Ocean Life Institute, National Science Foundation grant OCE-1536782, Department of Land and Natural Resources of the State of Hawai'i, Whale Tales Maui, Pride of Maui, the PADI Foundation, and the National Marine Sanctuary Foundation. We thank Lee James of Ultimate Whale Watch Maui, Russell Hanson, Christina Cantellops, Heather Spillane, Larissa Treese, Marina Treese, Mark Deakos, and Jennifer Kogan for donating vessel and personal time to help with EAR recoveries and re-deployments. We also thank 3 anonymous reviewers for their insightful suggestions on the manuscript.

\section{LITERATURE CITED}

Ainslie MA, Miksis-Olds JL, Martin B, Heaney K, de Jong CAF, von Benda-Beckmann AM, Lyons AP (2018) ADEON underwater soundscape and modeling metadata standard. Version 1.0. Technical report by JASCO Applied Sciences for ADEON Prime Contract No. M16PC00003. University of New Hampshire, Durham, NH

Au WWL, Green M (2000) Acoustic interaction of humpback whales and whale-watching boats. Mar Environ Res 49: 469-481

$\mathrm{Au}$ WWL, Mobley JR Jr, Burgess WC, Lammers MO (2000) Seasonal and diurnal trends of chorusing humpback whales wintering in waters off Western Maui. Mar Mamm Sci 16:530-544

Au WWL, Pack AA, Lammers MO, Herman LM, Deakos $\mathrm{MH}$, Andrews K (2006) Acoustic properties of humpback whale songs. J Acoust Soc Am 120:1103-1110

Baker CS, Herman LM (1981) Migration and local movement of humpback whales (Megaptera novaeangliae) through Hawaiian waters. Can J Zool 59:460-469

*Baker CS, Herman LM (1984) Aggressive behavior between humpback whales (Megaptera novaeangliae) wintering in Hawaiian waters. Can J Zool 62:1922-1937

*Baker CS, Herman LM, Perry A, Lawton WS, Straley JM, Straley JH (1985) Population characteristics and migration of summer and late-season humpback whales (Megaptera novaeangliae) in southeastern Alaska. Mar Mamm Sci 1:304-323

Baker CS, Herman LM, Perry A, Lawton WS and others (1986) Migratory movement and population structure of humpback whales (Megaptera novaeangliae) in the central and eastern North Pacific. Mar Ecol Prog Ser 31: 105-119

Ballance LT, Pitman RL, Fiedler PC (2006) Oceanographic influences on seabirds and cetaceans of the eastern tropical Pacific: a review. Prog Oceanogr 69:360-390

Barber RT, Chavez FP (1983) Biological consequences of El Niño. Science 222:1203-1210

Begon M, Townsend CR, Harper JL (2006) Ecology: from individuals to ecosystems. Blackwell Publishing, Malden, MA

Benson SR, Croll DA, Marinovic BB, Chavez FP, Harvey JT (2002) Changes in the cetacean assemblage of a coastal upwelling ecosystem during El Niño 1997-98 and La Niña 1999. Prog Oceanogr 54:279-291

Bond NA, Cronin MF, Freeland H, Mantua N (2015) Causes and impacts of the 2014 warm anomaly in the NE Pacific. Geophys Res Lett 42:3414-3420

*Bown MR, Corkeron PJ, Hale PT, Schultz KW, Bryden MM (1995) Evidence for a sex-segregated migration in the 
humpback whale (Megaptera novaeangliae). Proc R Soc B 259:229-234

Calambokidis J, Falcone EA, Quinn TJ II, Burdin AM and others (2008) SPLASH: Structure of Populations, Levels of Abundance and Status of Humpback Whales in the North Pacific. Final report for Contract AB133F-03-RP00078 from Cascadia Research. US Department of Commerce Western Administrative Center, Seattle, WA

Cartwright R, Venema A, Hernandez V, Wyels C, Cesere J, Cesere D (2019) Fluctuating reproductive rates in Hawaii's humpback whales, Megaptera novaeangliae, reflect recent climate anomalies in the North Pacific. R Soc Open Sci 6:181463

Cavole LM, Demko AM, Diner RE, Giddings A and others (2016) Biological impacts of the 2013-2015 warm-water anomaly in the Northeast Pacific: winners, losers, and the future. Oceanography 29:273-285

Chen J (2017) Acoustic ecology of humpback whales (Megaptera novaeangliae) in the Hawaiian Archipelago. PhD dissertation, University of Hawai'i at Mānoa, Honolulu, HI

Childerhouse S, Jackson J, Baker CS, Gales N, Clapham PJ, Brownell RL Jr (2008) Megaptera novaeangliae (Oceania subpopulation). The IUCN Red List of Threatened Species 2008: eT132832A3463914. https://dx.doi.org/ 10.2305/IUCN.UK.2008.RLTS.T132832A3463914.en

Cholewiak DM, Cerchio S, Jacobsen JK, Urbán-R J, Clark CW (2018) Songbird dynamics under the sea: acoustic interactions between humpback whales suggest song mediates male interactions. R Soc Open Sci 5:171298

Clapham PJ (2008) Humpback whale. In: Perrin WF, Würsig B, Thewissen JGM (eds) Encyclopedia of marine mammals, $2^{\text {nd }}$ edn. Academic Press, New York, NY, p 582-584

Craig AS, Herman LM (1997) Sex differences in site fidelity and migration of humpback whales (Megaptera novaeangliae) to the Hawaiian Islands. Can J Zool 75: 1923-1933

Craig AS, Herman LM, Gabriele CM, Pack AA (2003) Migratory timing of humpback whales (Megaptera novaeangliae) in the Central North Pacific varies with age, sex and reproductive status. Behaviour 140:981-1001

Currie JJ, Stack SH, Davidson E, Kaufman GD, Martinez E (2014) Results from two years of line transect surveys utilizing surprise encounters and near-misses as proxies of vessels collisions with humpback whales (Megaptera novaeangliae) in the four-island region of Maui, Hawai'i, USA. Document SC/65b/HIM01 presented to the IWC Scientific Committee, Bled

Currie JJ, Stack SH, Kaufman GD (2017) Modelling whalevessel encounters: the role of speed in mitigating collisions with humpback whales (Megaptera novaeangliae). J Cetacean Res Manag 17:57-63

Darling JD, Bérubé M (2001) Interactions of singing humpback whales with other males. Mar Mamm Sci 17:570-584

* Darling JD, Jones ME, Nicklin CP (2006) Humpback whale songs: Do they organize males during the breeding season? Behaviour 143:1051-1101

Darling JD, Jones ME, Nicklin CP (2012) Humpback whale (Megaptera novaeangliae) singers in Hawaii are attracted to playback of similar song. J Acoust Soc Am 132: 2955-2958

Di Lorenzo E, Mantua N (2016) Multi-year persistence of the 2014/15 North Pacific marine heatwave. Nat Clim Change 6:1042-1047
Fowler Cw (1981) Dependence as related to life history strategy. Ecology 62:602-610

Frankel AS (1994) Acoustic and visual tracking reveals distribution, song variability and social roles of humpback whales in the Hawaiian waters. PhD dissertation, University of Hawai'i at Mānoa, Honolulu, HI

*Gentemann CL, Fewings MR, García-Reyes M (2017) Satellite sea surface temperatures along the West Coast of the United States during the 2014-2016 northeast Pacific marine heat wave. Geophys Res Lett 44:312-319

Helble TA, Guazzo RA, Martin CR, Durbach IN and others (2020) Lombard effect: Minke whale boing call source levels vary with natural variations in ocean noise. J Acoust Soc Am 147:698

*Herman LM (2017) The multiple functions of male song within the humpback whale (Megaptera novaeangliae) mating system: review, evaluation, and synthesis. Biol Rev Camb Philos Soc 92:1795-1818

Herman LM, Antinoja RC (1977) Humpback whales in the Hawaiian breeding waters: population and pod characteristics. Sci Rep Whales Res Inst 29:59-85

Herman LM, Forestell PH, Atinoja RC (1980) The 1976/77 migration of humpback whales into Hawaiian waters: composite description. Report No. MMC-77/19. Final Report to US Marine Mammal Commission in fulfillment of Contract MM7ACO14. University of Hawaii, Honolulu, HI

Johnston DW, Chapla ME, Williams LE, Matthila DK (2007) Identification of humpback whale Megaptera novaeangliae wintering habitat in the Northwestern Hawaiian Islands using spatial habitat modeling. Endang Species Res 3:249-257

Jurasz CM, Jurasz VP (1979) Feeding modes of the humpback whale, Megaptera novaeangliae, in southeast Alaska. Sci Rep Whales Res Inst 31:69-83

Kraus SD, Brown MW, Caswell H, Clark CW and others (2005) North Atlantic right whales in crisis. Science 309: 561-562

* L'Heureux ML, Takahashi K, Watkins AB, Barnston AG and others (2017) Observing and predicting the 2015/16 El Niño. Bull Am Meteorol Soc 98:1363-1382

*Lammers MO, Brainard RE, Au WW, Mooney TA, Wong KB (2008) An ecological acoustic recorder (EAR) for longterm monitoring of biological and anthropogenic sounds on coral reefs and other marine habitats. J Acoust Soc Am 123:1720-1728

KLammers MO, Fisher-Pool PI, Au WWL, Meyer CG, Wong KB, Brainard RE (2011) Humpback whale Megaptera novaeangliae song reveals wintering activity in the Northwestern Hawaiian Islands. Mar Ecol Prog Ser 423: 261-268

Lammers MO, Pack AA, Lyman EG, Espiritu L (2013) Trends in collisions between vessels and North Pacific humpback whales (Megaptera novaeangliae) in Hawaiian waters (1975-2011). J Cetacean Res Manag 13:73-80

Levine AFZ, McPhaden MJ (2016) How the July 2014 easterly wind burst gave the 2015-2016 El Niño a head start. Geophys Res Lett 43:6503-6510

*Mackas DL, Galbraith M (2002) Zooplankton community composition along the inner portion of Line P during the 1997-1998 El Niño event. Prog Oceanogr 54:423-437

Mantua NJ, Hare SR, Zhang Y, Wallace JM, Francis RC (1997) A Pacific Interdecadal Climate Oscillation with impacts on salmon production. Bull Am Meteorol Soc 78: 1069-1080 
Mobley JR Jr, Bauer GB, Herman LM (1999) Changes over a ten-year interval in the distribution and relative abundance of humpback whales (Megaptera novaeangliae) wintering in Hawaiian waters. Aquat Mamm 25:63-72

Mobley JR Jr, Spitz SS, Grotefendt R (2001) Abundance of humpback whales in Hawaiian waters: results of 19932000 aerial surveys. Hawaiian Islands Humpback Whale National Marine Sanctuary, Office of National Marine Sanctuaries, National Oceanic and Atmospheric Administration, Honolulu, HI

Moore SE (2008) Marine mammals as ecosystem sentinels. J Mammal 89:534-540

Neilson JL, Gabriele CM, Taylor-Thomas LF (2017) Humpback whale monitoring in Glacier Bay and Adjacent Waters 2016. Natural Resource Report NPS/GLBA/NRR2017/1503. National Park Service, Fort Collins, CO

Neilson JL, Gabriele CM, Taylor-Thomas LF (2018) Humpback whale monitoring in Glacier Bay and adjacent waters 2017: Annual progress report. Natural Resource Report NPS/GLBA/NRR - 2018/1660, National Park Service, Fort Collins, CO

Newman M, Alexander MA, Ault TR, Cobb KM and others (2016) The Pacific Decadal Oscillation, revisited. J Clim 29:4399-4427

NOAA (2019) Trends in humpback whale (Megaptera novaeangliae) abundance, distribution, and health in Hawai'i and Alaska: report from a meeting held on November 27-28, 2018. NOAA National Ocean Service, Office of National Marine Sanctuaries, Hawaiian Islands Humpback Whale National Marine Sanctuary and NOAA National Marine Fisheries Service, Pacific Islands Regional Office, Protected Resources Division, Honolulu, HI

NOAA NMFS (2016) Endangered and threatened Species; identification of 14 Distinct Population Segments of the humpback whale (Megaptera novaeangliae) and revision of species-wide listing. Fed Register 81:62260-62320

Noad MJ, Dunlop RA, Mack AK (2017) Changes in humpback whale singing behavior with abundance: implications for the development of acoustic surveys of cetaceans. J Acoust Soc Am 142:1611

Payne RS, McVay S (1971) Songs of humpback whales. Science 173:585-597

Piatt JF, Parrish JK, Renner HM, Schoen SK and others (2020) Extreme mortality and reproductive failure of common murres resulting from the northeast Pacific marine heatwave of 2014-2016. PLOS ONE 15:e0226087

R Core Team (2016) R: a language and environment for statistical computing. R Foundation for Statistical Computing, Vienna

Rocha RC Jr, Clapham PJ, Ivashchenko Y (2015) Emptying the oceans: a summary of industrial whaling catches in the 20th century. Mar Fish Rev 76:37-48

Rudd AB (2015) Investigating the movement and seasonal occurrence of cetaceans in Hawai'i using sound. PhD dissertation, University of Hawai'i at Mānoa, Honolulu, HI

Editorial responsibility: Jeremy Kiszka,

North Miami, Florida, USA
Seger KD, Thode AM, Urbán-R J, Martínez-Loustalot $\mathrm{P}$, Jiménez-López ME, López-Arzate D (2016) Humpback whale-generated ambient noise levels provide insight into singers' spatial densities. J Acoust Soc Am 140:1581

Senigaglia V, Christiansen F, Bejder L, Gendron D and others (2016) Meta-analyses of whale-watching impact studies: comparisons of cetacean responses to disturbance. Mar Ecol Prog Ser 542:251-263

* Simmonds MP, Isaac SJ (2007) The impacts of climate change on marine mammals: early signs of significant problems. Oryx 41:19-26

Straley JM (1999) Overwintering North Pacific humpback whales in Alaskan waters. In: 13th biennial meeting of the Society for Marine Mammalogy, Kihei, Maui

* Tershy BR, Breese D, Alvarez-Borrego S (1991) Increase in cetacean and seabird numbers in the Canal de Ballenas during an El Niño-Southern Oscillation event. Mar Ecol Prog Ser 69:299-302

Tseng YH, Ding R, Huang Xm (2017) The warm Blob in the northeast Pacific - the bridge leading to the 2015/16 El Niño. Environ Res Lett 12:054019

พ Tsujii K, Akamatsu T, Okamoto R, Mori K, Mitani Y, Umeda $N$ (2018) Change in singing behavior of humpback whales caused by shipping noise. PLOS ONE 13:e0204112

* Tyack PL (1983) Differential response of humpback whales, Megaptera novaeangliae, to playback of song or social sounds. Behav Ecol Sociobiol 13:49-55

* Tyack PL, Whitehead H (1983) Male competition in large groups of wintering humpback whales. Behaviour 83: 132-154

Tynan CT (1999) Redistributions of cetaceans in the southeast Bering Sea relative to anomalous oceanographic conditions during the 1997 El Niño. In: Proc 1998 Science Board Symposium on the impacts of the 1997/98 El Nino event on the North Pacific Ocean and its marginal seas. PICES Sci Rep 10. North Pacific Marine Science Organization (PICES), Sydney

*Valsecchi E, Corkeron PJ, Galli P, Sherwin W, Bertorelle G (2010) Genetic evidence for sex-specific migratory behaviour in western South Pacific humpback whales. Mar Ecol Prog Ser 398:275-286

Whitney FA (2015) Anomalous winter winds decrease 2014 transition zone productivity in the NE Pacific. Geophys Res Lett 42:428-431

* Winn HE, Winn LK (1978) The song of the humpback whale Megaptera novaeangliae in the West Indies. Mar Biol 47: 97-114

*Winn HE, Thompson TJ, Cummings WC, Hain J, Hudnall J, Hays H, Steiner WW (1981) Song of the humpback whale-population comparisons. Behav Ecol Sociobiol 8:41-46

Wood S (2006) Generalized additive models: an introduction with R. Chapman \& Hall/CRC, Boca Raton, FL

Zimmer WMX (2011) Passive acoustic monitoring of cetaceans. Cambridge University Press, Cambridge

Submitted: March 29, 2020; Accepted: October 8, 2020

Proofs received from author(s): December 1, 2020 